\title{
Academic self-concept and emotion relations: Domain specificity and age effects
}

\author{
Thomas Goetz $^{\mathrm{a}, *}$, Hanna Cronjaeger ${ }^{\mathrm{a}}$, Anne C. Frenzel ${ }^{\mathrm{b}}$, Oliver Lüdtke ${ }^{\mathrm{c}}$, Nathan C. Hall ${ }^{\mathrm{d}}$ \\ a Department of Psychology, University of Konstanz and Thurgau University of Teacher Education, Germany \\ ${ }^{\mathrm{b}}$ Department of Psychology, University of Munich, Germany \\ 'Max Planck Institute for Human Development, Berlin, Germany \\ ${ }^{\mathrm{d}}$ Department of Human Development, University of Maryland, College Park, USA
}

\section{A R T I C L E I N F O}

\section{Keywords:}

Academic self-concept

Academic emotions

Enjoyment

Pride

Anxiety

Anger

Boredom

\begin{abstract}
A B S T R A C T
The present study investigated the relations between academic self concepts and the emotions of enjoy ment, pride, anxiety, anger, and boredom as experienced in mathematics, physics, German, and English classes ( $N$ 1710; grades 8 and 11). In line with our hypotheses derived from appraisal based emotion theories and self efficacy research, within domain relations between self concepts and emotions were relatively strong and notably stronger within quantitative domains (mathematics and physics) than ver bal domains (German and English). Also consistent with our hypotheses, stronger relations between self concepts and emotions were observed among older students. Self concept and emotion relations further differed as a function of the specific emotion assessed, with pride showing the strongest and boredom the weakest relations with academic self concepts in the four domains assessed. Methodological and educa tional implications as well as directions for future research are discussed.
\end{abstract}

\section{Introduction}

In recent years, considerable research has explored the role of self concept and emotions in the academic domain (Linnenbrink, 2006; Marsh, Craven, \& Mclnerney, 2003) due to their demon strated importance with respect to self regulated learning, achievement motivation, course enrollment, and career related decision making (see Bong \& Skaalvik, 2003; Efklides \& Volet, 2005; Schutz \& Pekrun, 2007; Skaalvik \& Skaalvik, 2008). However, it is both interesting and surprising that empirical research on aca demic self concepts on the one hand, and emotions on the other, have remained largely independent. As a consequence of limited research in which academic self concepts and students' emotions are investigated in a single study, few empirical findings exist con cerning the interrelations between academic self concept and emo tional experiences (e.g., academic enjoyment, anger, and boredom). Thus, critical research questions concerning the extent to which students' emotional experiences can be inferred from perceived competencies in the academic domain, and vice versa, remain a largely unexplored yet potentially productive avenue for future re search in educational psychology.

Investigating self concept/emotions interrelations is thus important in order to provide empirical evidence on the conceptual overlap between these ubiquitous yet independently evaluated

* Corresponding author. Address: University of Konstanz, Universitaetsstr. 10. D-78457 Konstanz, Germany. Fax: +49 (0) 7531884350.

E-mail address: thomas.goetz@uni-konstanz.de (T. Goetz). constructs in educational psychology research. In addition to theo retical considerations, knowledge concerning self concept/emo tions relations and how they are moderated by subject area (e.g., mathematics vs. English), grade level, and emotion type (e.g., enjoyment vs. pride) could also serve to inform and improve re search practices. For example, if self concept and emotions are very strongly interrelated and empirically indistinguishable, it may be more efficient to simply investigate only one of these con structs in a given study. Moreover, if strong interrelations are found for some emotions (e.g., anxiety) and not others (e.g., bore dom), only the more differentiated emotions could be assessed in addition to academic self concepts. Knowledge of how these rela tions are moderated by different subject domains and age is also important with respect to generalizability and future research. For example, as most contemporary educational studies on psy chosocial constructs are conducted within specific academic sub ject areas (e.g., mathematics) and grade levels, knowledge of how subject domain and age moderate the relations between academic self concept and emotions should contribute to more accurate hypotheses (e.g., for mathematics vs. English classes), and more efficient recruitment procedures (e.g., for conducting power analy ses to determine appropriate sample size for specific age groups; cf., Cohen, 1988, 1992).

Theoretical assumptions with respect to self concept/emotion relations can be derived from both appraisal based emotion theo ries (e.g., Scherer, Schorr, \& Johnstone, 2001) as well as empirical research on the self efficacy construct (Bandura, 1977, 1989, 1997). Accordingly, the present study hypotheses were formulated 
based on the proposed relations outlined in these approaches, with the primary assumption being that significant self concept/emo tion relations should be observed. However, following from previ ous empirical findings suggesting that the strength of self concept/ emotion relations may be significantly affected by subject area, grade level, and emotion type, each of these factors were also eval uated in the present study as potential variables moderating the strength of self concept/emotion relations.

More specifically, given the largely domain specific organiza tion of academic self concepts and emotions (Bong, 2001; Goetz, Frenzel, Pekrun, Hall, \& Lüdtke, 2007), we explored the extent to which self concept/emotion relations were moderated by subject area (i.e., quantitative domains of mathematics and physics, vs. verbal domains of German and English). Consistent with previous empirical research on academic emotion relations (Goetz et al., 2007), the moderating influence of age on self concept/emotion relations was also evaluated with respect to different age groups (8th vs. 11th grade). Finally, we analyzed how specific discrete emotions differ in the magnitude of their relations with academic self concept as would be expected based on the assumptions of popular categorization schemas in emotion research (i.e., outcome vs. activity focus). To summarize, the present study analyzed the general strength of relations between academic self concept and emotions and further explored the degree to which these relations differed as a function of subject domain, grade level, and emotion type.

\subsection{Academic self concept and emotions conceptual definitions}

In their classic and highly influential review, Shavelson, Hubner, and Stanton (1976) broadly defined self concept as a person's self perceptions formed through experience with and interpretations of one's environment (see also Marsh \& O'Mara, 2008). These self perceptions are influenced especially by evaluations of significant others, reinforcements, and attributions for one's own behavior. With respect to emotions, numerous definitions have been pro posed (see Kleinginna \& Kleinginna, 1981; Lewis \& Haviland Jones 2000). Prominent definitions to which numerous studies refer en tail a componential perspective (Damasio, 2004; Scherer, 1984) in which emotions are viewed as multi component, coordinated pro cesses of psychological subsystems including affective, cognitive, motivational, expressive, and peripheral physiological processes. Affective processes (e.g., nervous feelings in the case of anxiety) are assumed to be central to emotions, and to be physiologically bound to limbic subsystems (Fellous \& LeDoux, 2005). In contrast to the necessary and sufficient nature of the affective component, other components are considered supplemental yet important for further differentiating and describing emotional experiences (e.g. by describing peripheral physiological processes like heart rate, or expressive aspects such as smiling).

Most important for the present study is that from a structural perspective, both self concept and emotions can be seen as being multidimensional and hierarchical in nature (see Goetz, Hall, Fren zel, \& Pekrun, 2006; Marsh \& Ayotte, 2003; Marsh \& Shavelson, 1985). With respect to multidimensionality, relations involving self concept and emotions can be evaluated comparatively across domains, for instance, in academic as opposed to non academic settings (see Shavelson et al., 1976). Concerning their hierarchical nature, relations with self concept and emotions may also be ex plored at differing degrees of specificity or generality within a gi ven domain. For example, self concept and emotions related to the academic domain can be readily assessed with respect to more specific academic subdomains such as mathematics, science, and English classes, or even specific areas within a given subdomains (e.g. mathematics: geometry, algebra, statistics).
In the present study, both the multidimensional and hierarchi cal structure of self concept and emotions was accounted for by exploring their interrelations across different academic domains at a specific level of generalization (i.e., subject areas), namely mathematics, physics, German, and English. When analyzing rela tions between constructs, it is important to consider, and ideally, equate the level of generalization for each construct assessed (see Brunswik, 1952; Goetz et al., 2006). For example, analyzing relations between a global self concept measure (e.g., self concept in the academic domain) and emotions within a specific subject area (e.g., enjoyment in mathematics) should result in weaker rela tions than when both constructs are assessed at the same level of generalization. The same is true for the aspect of multidimension ality that occurs as a consequence of increasingly specific levels of analysis (e.g., general academic self concept vs. math or English related self concept). For example, a students' self concept related to mathematics should be more strongly related to feelings of pride concerning one's math proficiency than to pride related to their performance in English class.

Another important distinction in emotion research concerns the temporal generality of emotional experiences as reflected by the trait/state differentiation of emotion constructs (Cattell \& Scheier, 1961; Spielberger, 1972). In this approach, trait emotions are seen as habitual, recurring emotions typically experienced by an indi vidual whereas state emotions are viewed as emotions experi enced at a specific point in time. It is important to note that the fundamental characteristic separating trait from state emotions is temporal as opposed to situational generality, as trait emotions can also be assessed in a situation specific manner (e.g., trait math ematics anxiety). In self concept research, the trait/state distinc tion has rarely been discussed, with self concept having almost exclusively been investigated as a trait construct despite the possi bility of trait vs. state oriented assessments (e.g., "I have always done well in mathematics" vs. "I can do well in mathematics at this moment"). Consistent with predominantly trait based operational izations in previous self concept research, both self concept and emotions were evaluated as trait constructs in the present study so as to equate these variables with respect to not only multidi mensionality and hierarchical level of generalization, but also tem poral generality.

\subsection{Academic self concept and emotion relations}

The manner in which self concept and emotions constructs are interrelated has been addressed in the context of appraisal based emotion theories (Scherer et al., 2001) as well as self efficacy re search (Bandura, 1977, 1989). As self concept and self efficacy rep resent largely overlapping constructs (Bong \& Skaalvik, 2003), the relations observed between self efficacy and emotion measures may provide some insight into potential relations between self concept and emotion measures. More specifically, because both self concept and self efficacy reflect greater perceptions of per sonal control (Pekrun, 2006), and higher perceived control shows a clear pattern of relations with emotional experiences (Ruthig et al., 2008), it is reasonable to assume that academic emotions should show similar relations with self concept as with self efficacy.

Appraisal based emotion theories (see Scherer et al., 2001) argue that cognitive appraisals such as perceptions of personal compe tence or control are clearly related to the emotions experienced in that situation (e.g., enjoyment, anxiety). As academic self con cepts involve beliefs related to one's perceptions of academic con trol (e.g., physics; see Marsh, 1993; Shavelson et al., 1976), they are assumed to correspond with emotional experiences in the aca demic domain. High levels of perceived control are assumed to coincide with greater action outcome expectancies and adaptive 
action control behaviors (Skinner, 1996), with each, in turn, result ing in pleasant emotional experiences such as enjoyment, hope, and pride (see Pekrun, 2006). In contrast, low levels of perceived personal control should result in unpleasant emotions such as anx iety, anger, and hopelessness due to lower action outcome expec tancies and more maladaptive action control behaviors.

Self efficacy research may also provide an empirical rationale for anticipated self concept/emotion relations due to the notable con ceptual overlap between the self efficacy and self concept con structs. While academic self concept refers to knowledge and perceptions of oneself in achievement domains, academic self effi cacy refers to one's convictions that they can successfully perform given academic tasks (Bong \& Skaalvik, 2003). In self efficacy re search, this construct is viewed primarily as a mechanism of emo tion regulation. According to Bandura (1997), the three principal ways in which efficacy beliefs can impact emotional experiences is through its effects on (1) thoughts, (2) actions, and (3) emotions directly. With respect to thoughts, it is assumed that high efficacy beliefs allow one to construe, represent, and retrieve life events so as to elicit pleasant emotional experiences, and also contribute to the belief that perturbing thoughts can be controlled which fur ther elicits pleasant emotions. Concerning actions, it is assumed that high self efficacy beliefs facilitate the enactment of behaviors that impact one's environment in a manner that optimizes emo tional well being. Finally, affect oriented self efficacy beliefs are also hypothesized to contribute directly to a more positive emo tional profile, with the perceived ability to reduce aversive emo tional states assumed to correspond with actual reductions in adverse emotional experiences.

In sum, both appraisal based emotion theories as well as self efficacy research lead to the assumption that self concept and emotions are interrelated. However, the question arises as to how strongly these constructs are interrelated and whether the strength of these relations differs as a function of potential moder ating variables. The present study attempts to address each of these research questions by exploring not only the magnitude of relations between self concept and emotional experiences in the educational domain, but also the extent to which the academic do main (e.g., language courses vs. quantitative courses), students' age (i.e., grade level), and the specific emotion under investigation (e.g. pride vs. enjoyment) moderate the observed relations between these constructs.

\subsubsection{Strength of relations}

The theoretical assumption of significant relations between self concept and emotions has been confirmed in numerous stud ies (Bandura, 1997; Henson \& Chang, 1998; see also Reeve, Deci, \& Ryan, 2004; Shell \& Husman, 2008). Recent empirical research has found significant and strong relations between students' academic self concepts and their emotions (Goetz, Frenzel, Hall, \& Pekrun, 2008; Goetz, Pekrun, Hall, \& Haag, 2006). With respect to the va lence of academic self concept and emotion relations, findings clearly indicate that pleasant emotions (e.g., enjoyment, pride) show positive relations with self concepts, and unpleasant emo tions (e.g., anxiety, anger) show negative relations with academic self concepts (Frenzel, Pekrun, \& Goetz, 2007; Goetz et al., 2006; Pekrun, Elliot, \& Maier, 2006).

However, because these studies investigated self concept and emotions in different domains and age groups, and assessed differ ent emotions, it is consequently difficult to compare results across studies. Although all of these studies clearly show significant rela tions between academic self concept and emotions, the strength of relations was found to differ substantially between studies. One plausible explanation for the inconsistent strength of relations ob served may be that these relations are moderated by the academic domain in which self concept and emotions were assessed, the age group under investigation, or the specific emotions under investiga tion in each study.

\subsubsection{Domain specificity}

There exists no empirical research to date investigating whether the relations between self concept and emotions are do main specific in nature, that is, whether these relations differ as a function of subject domain (e.g., whether the strength of relations between self concept and anxiety in mathematics differs from the relation between both constructs in English). However, separate findings for motivational and emotional constructs are suggestive as to the potential moderating influence of domain on self con cept/emotion relations. Concerning motivational constructs, Bong (2001) found the pattern of relations for self efficacy, task value, and achievement goals (mastery, performance approach, perfor mance avoidance) to be relatively stable across different subject areas (mathematics, science, and languages). In contrast, Goetz et al. (2007) found the strength of relations among emotions (enjoyment, pride, anxiety, anger, and boredom) to significantly differ across domains (mathematics, physics, German, and Eng lish). These results showed the strongest within domain relations for mathematics, and the weakest relations for German classes, implying that academic emotions may be more interrelated in quantitative domains (e.g., sciences) than in verbal domains (e.g., English).

In interpreting these results, the question arises as to why the strength of self concept/emotion relations may differ as a function of subject domain. Goetz et al. (2007) speculate that relations be tween constructs should be more weakly interrelated in broadly defined domains (e.g., language courses) as compared to more homogeneous domains (e.g., quantitative courses). Language course curricula typically include a variety of study materials, ranging from poems and biographies, to technical or news reports on controversial topics. In contrast, the topics covered in quantita tive domains are more consistent in topic and format, involving primarily nonverbal, numeric content and problem solving exer cises (see also Dweck, 1986). This assertion is consistent with stud ies by Stodolsky and Grossman $(1995,2000)$ showing teachers to describe the subject of mathematics as more narrowly defined compared to English (e.g., having a "well defined body of knowl edge and skills to be taught"; Stodolsky \& Grossman, 2000, p. 168 ). Thus, greater consistency with respect to subject matter should contribute to classes in quantitative domains also being perceived by students as more narrowly defined than classes in language domains.

Therefore, relations between self concept and emotions are assumed to be stronger in more homogeneous domains (e.g., mathematics, physics) because of a more limited range of infor mation sources from which perceptions of competence and emo tions are derived. For example, students' perceived competence and emotions in mathematics are likely to be based primarily on the narrowly defined contents of their mathematics experi ences in the classroom. In contrast, because students' associa tions with heterogeneous domains (e.g., English) are typically more "diffuse" in nature, self concept/emotions relations are ex pected to be weaker in these subject areas. To summarize, empirical results from emotion research and assumptions con cerning the heterogeneity of subject areas together suggest that subject domain should moderate the strength of relations be tween self concept and emotions.

\subsubsection{Age effects}

Despite the lack of a theoretical model in which age effects on self concept/emotion relations are explicitly addressed, it has long been hypothesized that students' mental representations of spe cific subject domains become more concrete with age (i.e., increas 
ing clarity of constructs with students' age; Chapman \& Turner, 1995; Stipek \& Mac Iver, 1989; Wigfield, 1994; Wigfield et al., 1997). As specific subject areas tend to be increasingly perceived as homogeneous domains with increasing age, it follows that the strength of relations between the self concept/emotion constructs within these domains should also increase with age.

Empirical findings are consistent with this assertion in showing the relations between positive affect (e.g., interest, task value) and self concept to become stronger from grades 16 (e.g., Deci \& Ryan, 1985; Marsh, Craven, \& Debus, 1999; Marsh et al., 2003; see also Wigfield et al., 1997). However, limited previous research explor ing age differences in self concept or emotions found no differ ences in the strength of relations for younger as compared to older students. Bong's (2001) study indicates that relations be tween different motivational constructs in the domains of mathe matics, science, and languages did not differ in middle vs. high school students. In the same vein, Goetz et al. (2007) found the relations between specific emotional experiences in the domains of mathematics, physics, German, and English to be the same for middle and high school students. Thus, despite a plausible theo retical basis for the assumption that self concept/emotions rela tions should be stronger in older students, empirical findings concerning this assumption are mixed.

\subsubsection{Academic emotions}

Regarding the valence of self concept/emotion relations, empir ical studies have found pleasant emotions (e.g., enjoyment, pride) to have positive relations with self concept, and unpleasant emo tions (e.g., anxiety, anger) to be negatively related with academic self concepts (Frenzel et al., 2007; Goetz et al., 2006; Pekrun et al., 2006). However, our review of the research literature re vealed no empirical studies evaluating the strength of self con cept/emotion relations as moderated by the specific pleasant or unpleasant emotion assessed. Nonetheless, the theoretical distinc tion between activity and outcome related emotions outlined by Pekrun's (2006) represents an important theoretical dimension underlying students' emotional experiences that could contribute to differential self concept/emotion relations.

Whereas activity emotions pertain to ongoing achievement re lated tasks, outcome emotions refer to the consequences of these tasks (see also Pekrun et al., 2006). Pekrun (2006) also suggests that some emotions, such as enjoyment, may refer both to activi ties and outcomes. Because the main focus of academic self con cept is on outcomes (e.g., "I get good marks in mathematics classes"; SDQ item; Marsh, 1988), relations between self concept and emotions should be stronger for outcome related emotions (including pride and anxiety) than for activity related emotions (including boredom). Concerning emotions that are both activity and outcome related (including enjoyment and anger), the strength of their relations with self concepts is expected to be stronger than for activity related emotions yet weaker than for outcome related emotions. Scattered empirical results support the above hypotheses in showing academic boredom to have rela tively weak relations with academic self concept, the emotions of enjoyment, anxiety, and anger to have stronger relations, and feel ings of pride to have the strongest relations (Frenzel et al., 2007; Goetz, 2004; Goetz et al., 2006).

\section{Research hypotheses}

The present study examined four research hypotheses concern ing the relations between academic self concept and emotions with respect to the overall strength of relations, and whether the strength of relations differs as a function of domain, grade level, and emotion type. In selecting the specific emotions to be assessed, both outcome and activity related emotions found to be salient in academic settings were included (Goetz, 2004; Pekrun, 2006; Pek run, Goetz, Titz, \& Perry, 2002). In total, five academic emotions were assessed including pride (pleasant, outcome related), enjoy ment (pleasant, activity and outcome related), anxiety (unpleas ant, outcome related), anger (unpleasant, activity and outcome related), and boredom (unpleasant, activity related). To assess po tential age related differences in self concept/emotion relations, both 8 th and 11th grade students were assessed consistent with previous studies on within domain relations of motivational and emotional constructs (Bong, 2001; Goetz et al., 2007). With respect to the academic domains in which each emotion was evaluated, we focused on two quantitative domains (mathematics, physics) and two verbal domains (German, English) typically included in both middle and high school curriculae in Germany. ${ }^{1}$

Hypothesis 1. Strength of relations. Based on appraisal based emotion theories, self efficacy research, and previous empirical findings, moderate to strong relations overall were anticipated between academic self concepts and emotions.

Hypothesis 2. Relations as a function of domain. Consistent with theoretical assumptions concerning the heterogeneity of subject areas as well as previous results, it was anticipated that within domain relations would be stronger in the more homogeneous, quantitative domains of mathematics and physics, than in the more heterogeneous, verbal domains of German and English.

Hypothesis 3. Relations as a function of age. Following from theo retical assumptions and empirical findings on 1 st to 6 th grade stu dents' mental representations of specific subject domains, it was hypothesized that the relations between self concept and emo tions would be stronger among older students (grade 11) than among younger students (grade 8 ).

Hypothesis 4. Relations as a function of emotion type. Based on pre vious studies supporting the theoretical differentiation between outcome and activity related emotional experiences, academic self concepts were expected to be most strongly related to emo tions that were clearly outcome related (pride, anxiety), moder ately related to emotions with both an outcome and activity focus (enjoyment, anger), and have the weakest relations with the activity related emotion of boredom.

\section{Method}

\subsection{Sample and data collection}

The sample consisted of 1710 German high school students ( $44 \%$ female) with a mean age of 15.71 years $(S D=1.64)$. Two grade levels were assessed, including 973 students from grade 8 ( $44 \%$ fe male; mean age 14.37 years, $S D=.57$; range: $[12.17 ; 17.75])$, and 737 students from grade 11 (44\% female; mean age 17.46 years, $S D=.63$; range: $[16.17 ; 20.58])$. Participants were recruited from

1 In the present study we exclusively refer to within-domain relations between self-concept and emotions and do not analyze between-domain relations. In othe words, we refer to the relations between self-concept and emotions within specific domains (e.g., self-concept in mathematics and pride in mathematics) but not on the relations across domains (e.g., self-concept in mathematics and pride in English). While between-domain relations of a specific construct are important to investigate (e.g., self-concept in mathematics and self-concept in English) between-domain relations of different constructs are less important both from a theoretical and practical perspective. For example, a teacher might want to know whether he can infer from a students' self-concept in mathematics his or her self-concept in English. However, it is likely less important for him whether he can infer from a students' selfconcept in mathematics his or her pride in English. 
a total of 73 classes (40/33 classes in grades 8/11; class size: $M=23.42, S D=4.68 ;$ Grades $8 / 11: M=24.33 / 22.33, S D=4.71$ / 4.46). Data collection took place during the second part of the aca demic year and was conducted by trained testing personnel using fully standardized student questionnaires. Participants were tested in a classroom setting and took part on a voluntary basis. To pre vent participants from explicitly focusing on comparisons between the different subject areas, items referring to different domains were located in different parts of the questionnaire booklets. There was a negligible amount of missing questionnaire data due to stu dent nonresponse $(0.5 \%$ missing data at the item level).

\subsection{Study measures}

\subsubsection{Academic self concepts}

To evaluate students' academic self concept in the domains of mathematics, physics, German, and English, items from the Ger man version of the Self Description Questionnaire were employed (SDQ; Marsh, 1988, 1990; Marsh \& O'Neill, 1984; see Kunter et al., 2002 for the German version), which is considered one of the best self concept instruments available (Byrne, 1996; Marsh, 1990, 1993; Marsh \& Craven, 1997). The SDQ assesses self concept as a trait construct involving habitual judgments of one's personal competence in a given domain. Because of instrument length lim itations, four items from the SDQ were selected (cf., four item emo tion scales). Included are three items from the SDQ previously selected by OECD statistical experts for use in the mathematics version of the scale assessed in the PISA 2000 study (Organisation for Economic Cooperation, 2001; items Sc_1, Sc_2, Sc_3; see Appendix A). An additional item from the SDQ was also included in the present self concept scale (Sc_4; see Appendix A). The three item PISA scale evaluated in previous studies was found to be highly representative of the larger 10 item mathematics self concept measure (see Trautwein, Luedtke, Marsh, Koeller, \& Baum ert, 2006). The fourth item included in the present self concept measure was highly correlated with the three item scale and im proved upon the reliability of the original PISA measure. As such, the present four item measure is assumed to be a valid and reliable measure of academic self concept.

Parallel item wordings were used in the assessment of academic self concept in four subject domains (four items per scale), with a to tal of 16 self concept items included in the questionnaire (4 domains $\times 4$ items per scale). In order to avoid redundancy between our emotion and self concept scales, we selected items from the SDQ that focused exclusively on the cognitive as opposed to affective components of students' self concepts (e.g., "I have always done well in [DOMAIN] classes"; see Bong \& Clark, 1999 for a discussion of the distinction between cognitive evaluative and affective com ponents of academic self concepts). The response format consisted of a 5 point Likert scale ranging from 1 (strongly disagree) to 5 (strongly agree). Scale means, standard deviations, and Cronbach's alphas for the self concept measures are provided in Appendix B. Standardized alphas for the self concept scales ranged from .82 to .91 in the grade 8 sample, and from .85 to .92 in the grade 11 sample. Zero order correlations among self concept scales are presented separately for the two grade levels in Appendix C.

\subsubsection{Academic emotions}

To assess the academic emotions of enjoyment, pride, anxiety, anger, and boredom in the domains of mathematics, physics, Ger man, and English, emotion measures concerning students' feelings toward classroom learning (i.e., as opposed to test taking or home work) were adapted from the mathematics version of the Achieve ment Emotions Questionnaire ([AEQ M]; Pekrun, Goetz, \& Frenzel, 2005). With respect to the trait/state distinction in emotion research (Cattell \& Scheier, 1961; Spielberger, 1972), trait oriented, habitual academic emotions were evaluated using the AEQ $M$. The specific AEQ $M$ items address multiple proposed components of emotion experiences (e.g., Damasio, 2004; Scherer, 1984). In each scale, the primary affective component was assessed as were supplemental physiological, motivational, and expressive emotion components. The AEQ $M$ as originally developed in the German language (later translated to English) was employed in the present study.

In choosing which emotions to be assessed, three selection cri teria were used. First, we wanted to assess both pleasant and unpleasant emotions. Second, we wished to evaluate emotions that differed with respect to having an outcome vs. activity focus (see Pekrun, 2006). Third, emotions that are particularly salient in aca demic settings were desired, as indicated by a review of the educa tional research literature (see Goetz, 2004; Pekrun et al., 2002). As a result of these three criteria, the following five emotions were as sessed: enjoyment (pleasant, activity and outcome related), pride (pleasant, outcome related), anxiety (unpleasant, outcome re lated), anger (unpleasant, activity and outcome related), and boredom (unpleasant, activity related).

Parallel item wordings were used to assess the five emotional experiences in four subject domains (four items per scale), result ing in a total of 80 emotion items in the study questionnaire (5 emotions $\times 4$ domains $\times 4$ items per scale). All emotion items are shown in Appendix A. Sample items were as follows: "I am looking forward to [DOMAIN] classes" for enjoyment, "I am proud of the contributions I make in [DOMAIN] classes" for pride, "I feel tense and nervous in [DOMAIN] classes" for anxiety, "I am angry in [DO MAIN] classes" for anger, and "I get bored in [DOMAIN] classes" for boredom. The response format consisted of a 5 point Likert scale ranging from 1 (strongly disagree) to 5 (strongly agree). Previous studies strongly support the convergent and divergent validity of the AEQ M scales (Pekrun et al., 2005) and the domain specific emotion measures used in the present study (Goetz et al., 2007).

The means, standard deviations, and Cronbach's alphas for all 20 emotion scales (5 emotions $\times 4$ domains) are provided in Appendix B, and are presented separately for the two grade levels. Standardized alphas for the emotion scales range from .73 to .91 $(M d n=.85)$ in the grade 8 sample, and from .69 to .93 $(M d n=.89)$ in the grade 11 sample. With one exception (anxiety in German, grade 11), each of the 40 alpha levels observed were above .70. Zero order correlations among the emotion scales as well as between the emotion and achievement measures are pre sented separately for the two grade levels in Appendix D, with zero order correlations between the emotion and self concept scales shown in Appendix E.

\subsubsection{Academic achievement}

To investigate the convergent validity of the domain specific self concept measures, students' self reported achievement out comes in mathematics, physics, German, and English (midterm grades) were also included in our analysis on within domain rela tions of self concept and emotions. It was anticipated that strong relations between academic achievement and self concept would be observed within a given domain. In the German school system, midterm grades are typically based on one written exam in each subject area completed during the first half of the academic year, combined with scores on course specific oral exams. Grades range from 1 (very good) to 6 (insufficient), with higher numbers repre senting poorer achievement. To allow for coefficients involving these achievement measures to be interpreted in a more intuitive manner, students' grades were inverted such that higher numbers indicated better performance. Means and standard deviations for the achievement data are presented in Appendix B, and zero order correlations among the achievement measures are outlined in Appendix D. Zero order correlations among the achievement and self concept measures are shown in Appendix E. 


\subsection{Data analysis}

As outlined in the study hypotheses, the main focus of our study was on the bivariate relations of academic self concept and emo tions. However, considering the large number of relations to be as sessed, a higher order analysis was employed in which a single index reflected the strength of relations between self concept and all emotional experiences in one domain and grade level. This index ranges from 0 to 1 (higher values $=$ stronger relations) and can directly be compared across domains and grade levels. As such, these specific indices were used to analyze the strength of relations between self concept and emotions (Hypothesis 1) and also to compare the strength of within domain relations across domains (Hypothesis 2) and grade levels (Hypothesis 3). To calculate this in dex, 3 level multi level analyses (hierarchical linear modeling, HLM; Raudenbush \& Bryk, 2002) were conducted using Mplus 5.0 software (Muthén \& Muthén, 1998 2007).

To assess the relations between academic self concept and emo tions in specific domains, structural equation modeling (SEM) was used to allow for the disattenuated relationships between the vari ables under investigation to be evaluated. In the SEM analyses, the hierarchical structure of the study data was taken into account (i.e., students within classes), as students within the same class are on average more similar than students from different classes. Thus, the standard errors resulting from routine standard procedures are typically downwardly biased (Hox, 2002). To correct for potential bias associated with class membership. SEM analyses were also con ducted with Mplus 5.0 using the complex sample option.

\section{Results}

\subsection{Strength of relations (Hypothesis 1)}

A fully unconditional 3 level hierarchical model was evaluated in which information was provided concerning the outcome vari ability on each of the three levels assessed (see Fig. 1; Raudenbush \& Bryk, 2002). We posit that the relative sizes of proportions of these variances allow for inferences about the degree of homoge neity (see Goetz et al., 2007; Hox, 2002), and consequently, about the strength of within domain relations. We created these 3 level models separately for the four domains and the grade 8 and 11 samples in order to have information on the strength of within do main relations for the different domains and the two age groups.

In our 3 level hierarchical model (see Fig. 1), the variance of $Y_{i j k}$ $\left[\operatorname{Var}\left(Y_{i j k}\right)\right]$ was defined as variance of the domain specific item $i$ (all self concept items [ $n=4]$ and emotion items [ $n=20]$ within a do main; level 1). Self concept items were nested within the domain specific self concept scale $j$ (level 2) and emotion items were nested within the emotion transcending scale $j$ (also level 2). Both scales were nested within domain specific score of person $k$ (level 3 ) representing a self concept and emotion transcending person score. Thus, our 3 level hierarchical model located scale items on level 1, total scales on level 2, and individual persons on level 3.

As enjoyment and pride represent pleasant emotions and anxi ety, anger, and boredom unpleasant emotions, it would not have been meaningful to aggregate all five emotions into a single score. Thus, we inverted all unpleasant emotion items (items referring to anxiety, anger, and boredom) for the analysis of within domain relations. Consequently, all items can be interpreted as indicators of pleasant emotions, or conversely, the absence of unpleasant emotions (cf., Goetz et al., 2007 for this approach).

The variance of $Y_{i j k}$ can be portioned into three parts (Rauden bush \& Bryk, 2002): $\operatorname{Var}\left(Y_{i j k}\right)=\operatorname{Var}\left(u_{00 k}\right)+\operatorname{Var}\left(r_{0 j k}\right)+\operatorname{Var}\left(e_{i j k}\right)=$ $\tau_{\beta}+\tau_{\pi}+\sigma^{2}$ with $u_{00 k}$ being the level 3 residuum (person level), $r_{0 j k}$ being the level 2 residuum (scale level), and $e_{i j k}$ being the level 1 residuum (item level). Based on these variance components, an index $h$ (se) (se stands for self concept/emotion) of the homoge neity of the two level 2 scales (self concept scale, pleasant emotion transcending scale) referring to the same domain can be calculated: $h(\mathrm{se})=\tau_{\beta} /\left(\tau_{\beta}+\tau_{\pi}\right)$. That is, $h(\mathrm{se})$ reflects the proportion of the level 3 variance in the total variance of levels 2 and 3. $h(\mathrm{se})$ consequently is an index for the homogeneity of level 2 constructs that takes the heterogeneity of level 1 constructs (items within self concept and emotions scales) into account.

In other words, $h(\mathrm{se})$ indicates the strength of within domain relations of the self concept and the pleasant emotion transcend ing scales when controlling for heterogeneity of the items within scales. As such, the present analysis controls for unreliability in the self concept scale (four items referring to self concept, level 1 ), unreliability in the emotion scale (20 items referring to emo tions, level 1 ), as well as differences in emotions (4 items for each of the 5 different emotions, level 1 ). The higher the $h($ se) value, the stronger the within domain relations between academic self con cept and emotions in that specific domain.

Table 1 shows results of our multi level analysis on the strength of within domain relations of self concept and academic emotions. The first three columns show the variance components of the three levels of our multi level analysis $\left(\tau_{\beta}, \tau_{\pi}\right.$, and $\sigma^{2}$; referring to levels 3 [person level], 2 [scale level], and 1 [item level]). Most important for our research question is the homogeneity index $h$ (se) which takes the level 2 and level 3 variance components into account.

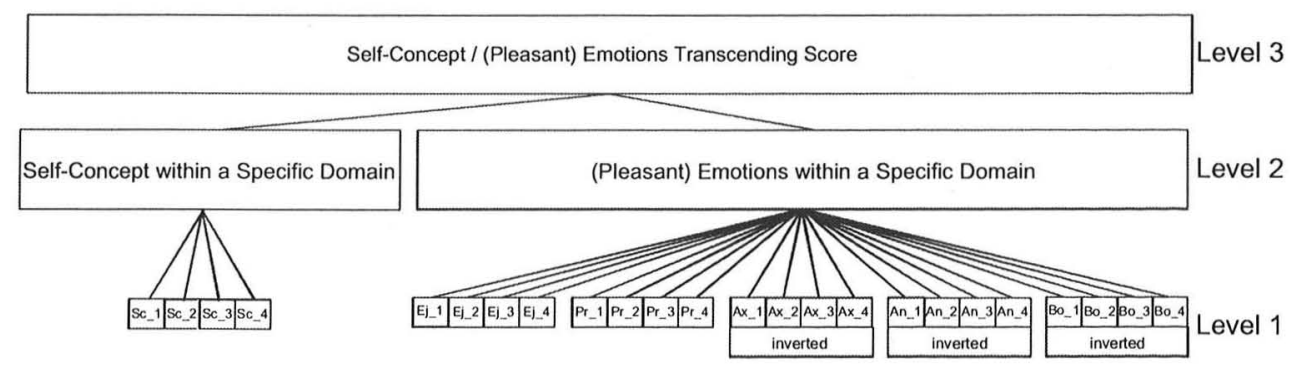

L3: domain-specific self-concept and (pleasant) emotions transcending score of a person (k)

L2: domain-specific self-concept and domain-specific (pleasant) emotions-transcending scales (j)

L1: domain-specific self-concept and domain-specific (pleasant) emotion items (i)

Fig. 1. Multi-level structure of within-domain relations of academic self-concept and emotions. Unpleasant emotion item scores (level 1) were inverted such that all item, scale, and person scores were indicators for pleasant emotions, or the absence of unpleasant emotions. 
Table 1

Results of multi-level analysis on the within-domain relations of academic emotions.

\begin{tabular}{|c|c|c|c|c|c|}
\hline & \multicolumn{3}{|l|}{ Variances } & \multirow{2}{*}{$\begin{array}{l}\text { Homogeneity of self-concept/ } \\
\text { emotions: Homogeneity } \\
\text { indices } h \text { (se) }\end{array}$} & \multirow{2}{*}{$\begin{array}{l}95 \% \text { confidence interval } \\
\text { of homogeneity indices } \\
h \text { (se) }\end{array}$} \\
\hline & $\begin{array}{l}\text { Level } 3\left(\tau_{\beta}\right) \text { self-concept } \\
\text { and emotion-transcending } \\
\text { scores of persons }\end{array}$ & $\begin{array}{l}\text { Level } 2\left(\tau_{\pi}\right) \text { self-concept scale } \\
\text { and emotion-transcending } \\
\text { scale within persons }\end{array}$ & $\begin{array}{l}\text { Level } 1\left(\sigma^{2}\right) \\
\text { self-concept and } \\
\text { emotion items }\end{array}$ & & \\
\hline \multicolumn{6}{|l|}{ Grade 8} \\
\hline Mathematics & .733 & .142 & 1.173 & .838 & $(.818-.857)$ \\
\hline Physics & .641 & .115 & 1.094 & .848 & $(.819-.878)$ \\
\hline German & .296 & .119 & 1.390 & .714 & $(.675-.753)$ \\
\hline English & .394 & .143 & 1.142 & .733 & $(.694-.773)$ \\
\hline \multicolumn{6}{|l|}{ Grade 11} \\
\hline Mathematics & .898 & .111 & 1.026 & .890 & $(.861-.920)$ \\
\hline Physics & .768 & .069 & 1.149 & .917 & $(.896-.939)$ \\
\hline German & .372 & .094 & 1.284 & .799 & $(.764-.834)$ \\
\hline English & .477 & .095 & 1.032 & .834 & $(.803-.865)$ \\
\hline
\end{tabular}

Note: All unpleasant emotion items (referring to anxiety, anger, and boredom) were inverted for this analysis. Consequently, all items were indicators of pleasant emotional experiences. Homogeneity index was calculated as follows: $h(\mathrm{se})=\tau_{\beta} /\left(\tau_{\beta}+\tau_{\pi}\right)$.

The $h(\mathrm{se})$ values across domains and grade levels were generally high and ranged from .714 (German, grade 8 ) to .917 (physics, grade 11$).^{2}$ This result suggests that academic self concept and emo tions are strongly interrelated, and as such, is consistent with Hypothesis $1 .^{3}$

\subsection{Relations as a function of domain (Hypothesis 2)}

The 95\% confidence interval of $h(\mathrm{se})$ shown in Table 1 was cal culated based on the standard error of $h(\mathrm{se}){ }^{4}$ Whether and to what amount these confidence intervals overlap indicates the extent to which the homogeneity indices differed from each other. In other words, confidence intervals show whether the strength of self con cept/emotion relations differs with respect to the domains in which both constructs were assessed. If the self concept/emotion relations differ with respect to the domain, subject domain can be considered a moderator of the strength of relations between those two con structs. The comparison of $h$ (se) within the two samples (grade $8 /$ 11) showed the confidence intervals for $h(\mathrm{se})$ to overlap for mathe

\footnotetext{
${ }^{2}$ HLM analysis accounting for class level as level 4 were also conducted using the MLwiN software (Rasbash, Browne, Healy, Cameron, \& Charlton, 2001). However, this and other software allowing for four-level models do not allow a direct calculation of standard errors of $h(\mathrm{se})$ and thus do not permit significant differences between indices with respect to domain and grade level to be observed (see Hypotheses 2 and 3 ). Results of the four-level analyses are very similar to the three-level findings reported in this study: The homogeneity indexes $\left[h(\mathrm{se})=\tau_{\beta} /\left(\tau_{\beta}+\tau_{\pi}\right)\right]$ of the four level model are as follows: grade $8 / 11=.824 / .866$ for mathematics, $.838 / .908$ for physics, $.701 / .790$ for German, and .720/.814 for English. Thus, the addition of a fourth level contributed to slightly decreased indices with the percentage decrease ranging from $0.98 \%$ to $2.76 \%$.

${ }^{3}$ The same analysis was also conducted controlling for achievement as a potential confound variable. The first step in this analysis regressed all self-concept items and pleasant emotion items (i.e., enjoyment, pride; inverted items for anxiety, anger, boredom) in a given domain on the corresponding achievement in that domain. This analysis was conducted separately for the four domains and for the grade 8 and 11 samples. The resulting residuals were included in a file located at the item level (level 1), upon which level 2 (scale level) and level 3 (person level) files were constructed by aggregating procedures. Thus, by including residuals at level 1 we calculated the strength of self-concept/emotion relations while controlling for achievement. In grade 8 , homogeneity indices controlling for achievement [ $h$ (se)] were .776 for mathematics, .791 for physics, .540 for German, and .670 for English. In grade 11, $h$ (se) were .814 for mathematics, 847 for physics, 618 for German, and 726 for English. These results show that although homogeneity indices decreased slightly when controlling for achievement, the pattern of results was very similar to that observed in the original analyses.

${ }^{4}$ To obtain standard errors for the homogeneity index $h(\mathrm{se})$, a three-level model was evaluated in Mplus for each domain (e.g., mathematics) and grade. As it is only possible to calculate two-level models in Mplus, we specified the first level as a constrained confirmatory factor analysis (see Bauer, 2003; Mehta \& Neale, 2005). By setting nonlinear constraints that could be specified in Mplus, standard errors for derived quantities like the homogeneity index $h(\mathrm{se})$ can be obtained. Using these standard errors, $95 \%$ confidence intervals were calculated.
}

matics and physics (quantitative domains) as well as for German and English classes (verbal domains) in both the grade 8 and $11 \mathrm{sam}$ ples. However, the confidence intervals for $h(\mathrm{se})$ for the quantitative vs. verbal domains did not overlap for either grade level ( 4 compar isons in each sample), with the exception of a slight overlap in con fidence intervals found between mathematics $([.861 ; 920])$ and English ( $[.803 ; 865])$ in grade 11 . Thus, these findings provide empir ical support for Hypothesis 2 in showing stronger within domain relations between self concept and emotions in the quantitative do mains of mathematics and physics as compared to the verbal do mains of German and English.

\subsection{Relations as a function of age (Hypothesis 3)}

Greater homogeneity index values $h(\mathrm{se})$ were found for the grade 11 sample as compared to the grade 8 sample (see Table 1 ). Confidence intervals of the homogeneity indices did not overlap when comparing across the grades within each of the four do mains. These results suggest that the homogeneity indices (i.e., $h(\mathrm{se})$ ) differed significantly between the two samples. Thus, in line with our assumption (Hypothesis 3), the relations between self concept and emotions within the different domains were clearly stronger for older students.

\subsection{Relations as a function of emotion type (Hypothesis 4)}

To analyze the relations between academic self concept and emotions within different domains (mathematics, physics, Ger man, English) in greater detail, structural equation modeling was employed (Muthén \& Muthén, 1998 2007). One analytical model was assessed for each of the four domains and conducted sepa rately for the grade 8 and 11 samples. For each domain specific model, latent domain specific factors were constructed for aca demic self concept and each of the five emotions (enjoyment, pride, anxiety, anger, and boredom). To investigate the convergent validity of the self concept measures, achievement outcomes were also included (as manifest variables) in each of the models (cf., Marsh, 1989; Marsh \& Yeung, 1996). A total of eight models were assessed (4 domains $\times 2$ samples), with each model consisting of six latent factors (domain specific academic self concept, five do main specific emotions) and one manifest achievement factor (do main specific academic achievement; see Fig. 2). Fit indices for each SEM model are presented in Table 2 (for detailed descriptions of the fit indices used, see Bentler (1990) [CFI]; Steiger and Lind (1980) [RMSEA]; Tucker and Lewis (1973) [NNFI]). The models showed acceptable overall fit. 


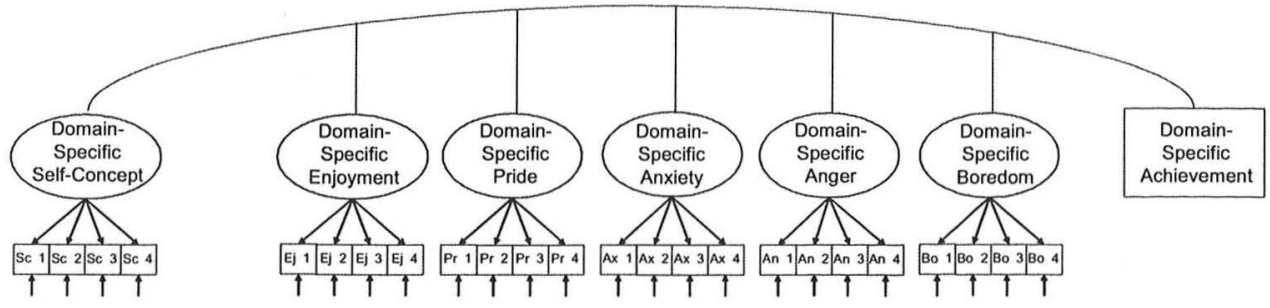

Fig. 2. Within-domain relations between academic self-concept, emotions, and achievement.

Table 3 presents the correlations between the latent self con cept factor, the latent emotion factors, and the manifest achieve ment variable for each of the four domains (separately for each grade level). Standard errors of the correlation coefficients are also shown in Table 3. The pattern of correlations between self concept and achievement scores indicated high convergent validity for the latent domain specific self concept factors. These correlations were strong in magnitude and ranged from .59 (German, grade 8) to .76 (mathematics, grade 11). As expected, all correlations be tween academic self concept and pleasant emotions were positive in valence, whereas all correlations between self concept and unpleasant emotions were negative.

Concerning the strength of relations between self concept and emotions, a clear overall picture emerged despite some differences between academic domains. Consistent with Hypothesis 4, rela tions between self concept and emotions (see Table 3 ) for both the grade 8 and 11 samples and in all domains were weak for the activity related emotion of boredom (range: $[-.23 ;-.47]$ / $[-.44 ;-.57]$, median: $-.38 /-.50$ for grades $8 / 11$ ). The outcome re lated emotion of pride showed very strong relations with academic self concept in both grade levels (range: $[.55 ; .84] /[.61 ; .88]$, med ian: $.75 / .79$ for grades $8 / 11$ ). However, an unanticipated pattern of results showed the outcome related emotion of anxiety to have similar relations with self concept as found for enjoyment and an ger, which are both activity and outcome related emotions (medi ans of correlations for self concept and enjoyment/anxiety/anger were $.62 /-.58 /-.52$ in grade 8 and $.74 /-.69 /-.63$ in grade 11 ). In sum, the correlation results showed the strongest relations with self concept for the emotion of pride, followed by enjoyment/anx iety/anger, and finally boredom. ${ }^{5}$

To illustrate the extent to which emotions differed with respect to correlations with academic self concept, absolute values of cor relations coefficients and their $95 \%$ confidence intervals are pre sented in Fig. 3. For example, concerning mathematics in grade 8 , self concept was most strongly related to pride, moderately related to enjoyment, anxiety, and anger, and most weakly related to bore

\footnotetext{
${ }^{5}$ The same analysis was also conducted controlling for achievement as a potential confound variable. The first step in this analysis regressed all self-concept items and emotion items in a given domain on the corresponding achievement in that domain This analysis was conducted separately for the four domains and for the grade 8 and 11 samples. The resulting residuals were used for structural equation modeling and take the hierarchical structure of our data (students within classes) into account (see Fig. 2 without achievement in the model). By including residuals at level 1 , we calculated the strength of self-concept/emotion relations while controlling for achievement. The 8 models (each 8 domains for grade levels 8 and 11) showed acceptable overall fit and a very similar pattern of correlations, with all correlations slightly decreasing when controlling for achievement. The medians for the selfconcept/emotion relations were as follows: enjoyment/pride/anxiety/anger/boredom in grade $8=59 / .72 /-.45 /-.39 /-.31$; in grade $11=.66 / .73 /-.54 /-.48 /-.37$. To evaluate the effect of achievement on self-concept/emotion relations, the 40 correlation coefficients obtained without controlling for achievement, and the 40 correlation coefficients obtained after controlling for achievement, were subjected to Fisher's z transformation (Cohen, 1988). The absolute values $(|q| s)$ of the 40 differences in the $z$ transformed correlations coefficients can be interpreted as the effects of achievement on the correlation coefficients. The mean of these 40 difference values is .15 (retransformed: also .15) showing that the effect of achievement on self-concept/ emotion relations was weak (see Cohen, 1988).
}

dom. Confidence intervals (95\%) were also found to strongly over lap for the emotions of enjoyment, anxiety, and anger, indicating that these emotions do not differ with respect to the strength of their relations with academic self concept.

\section{Discussion}

In the present study, the relations between academic self con cept and emotions (enjoyment, pride, anxiety, anger, and boredom) were evaluated in the context of four research questions. The first concerned the overall strength of self concept/emotion relations (Hypothesis 1), and the second involved the extent to which these relations differed across academic domains (quantitative domains of mathematics and physics, verbal domains of German and English; Hypothesis 2). The moderating role of age (grades 8 vs. 11) with re spect to the self concept/emotion relations (Hypothesis 3), and potentially differential relations for specific emotions (action vs. outcome oriented) were also explored (Hypothesis 4).

\subsection{Strength of relations between self concept and emotions}

Our initial study hypotheses suggested that moderate to strong relations between self concept and emotions should be observed as suggested by appraisal based emotion theories and self efficacy research. The present study provides clear empirical support for this assumption, showing strong self concept/emotion relations in all four subject domains assessed (mathematics, physics, Eng lish, German). As hypothesized, self concept was positively related to pleasant emotions (enjoyment, pride) and negatively related to unpleasant emotions (anxiety, anger, and boredom). However, it is important to note that none of the correlation coefficients was high enough to preclude the assessment of academic self concept and emotions as distinct theoretical constructs. Although some correla tions were strong in magnitude (e.g., relations between self con cept and pride), these coefficients were corrected for unreliability and thus represent the highest possible coefficients derivable from this data.

With the exception of pride in the quantitative domain, correla tions between self concept and emotions were of similar strength or lower than those between self concept and achievement. Our re sults thus suggest that not unlike self concept and academic achievement outcomes, self concept and emotion measures can be empirically differentiated. However, it is important to note that the self concept/achievement correlations (Table 3) were only partly disattenuated due to achievement being assessed as a mani fest variable. Thus, it can be assumed that the strength of the self concept/achievement relations was underestimated in the present study. The correlations between self concept and achievement can thus not be directly compared with those between self concept and emotions that were each evaluated as latent variables. Never theless, when comparing self concept/emotion relations with self concept/achievement relations at the manifest level (see Appendix E), the former (e.g., between self concept and pride) were the same or weaker in magnitude relative to the latter. Thus, when considered in contrast to research suggesting that self concept and achieve 
Table 2

Within-domain relations of academic emotion constructs - characteristics of the structural equation models.

\begin{tabular}{|c|c|c|c|c|c|c|c|c|c|c|}
\hline \multirow[b]{2}{*}{ Domain } & \multicolumn{5}{|l|}{ Grade 8} & \multicolumn{5}{|c|}{ Grade 11} \\
\hline & $\chi^{2}$ & $d f$ & NNFI & $\mathrm{CFI}$ & RMSEA & $x^{2}$ & $d f$ & NNFI & CFI & RMSEA \\
\hline Mathematics & 1567.35 & 255 & .89 & .91 & .073 & 1567.97 & 255 & .88 & .90 & .084 \\
\hline Physics & 1417.84 & 255 & .90 & .91 & .069 & 1302.57 & 255 & .89 & .91 & .075 \\
\hline German & 1251.15 & 255 & .89 & .91 & .059 & 1238.86 & 255 & .86 & .88 & .072 \\
\hline English & 1251.14 & 255 & .89 & .91 & .063 & 1273.06 & 255 & .88 & .90 & .074 \\
\hline
\end{tabular}

Note: $\mathrm{NNFI}=$ Bentler-Bonett Non-Normed Fit Index; $\mathrm{CFI}=$ Comparative Fit Index; RMSEA = Root Mean Square Error of Approximation.

Table 3

Relations between self-concept and emotions/achievement in different domains (with standard errors).

\begin{tabular}{|c|c|c|c|c|c|c|}
\hline Self-concept & Enjoyment & Pride & Anxiety & Anger & Boredom & Achievement \\
\hline \multicolumn{7}{|c|}{ Emotions/achievement grade 8} \\
\hline Mathematics & $.68(.025)$ & $.84(.018)$ & $-.68(.030)$ & $-.62(.033)$ & $-.44(.037)$ & $.68(.025)$ \\
\hline Physics & $.71(.023)$ & $.78(.024)$ & $-.63(.030)$ & $-.60(.035)$ & $-.47(.035)$ & $.60(.023)$ \\
\hline German & $.42(.040)$ & $.55(.032)$ & $-.51(.049)$ & $-.43(.047)$ & $-.23(.052)$ & $.59(.027)$ \\
\hline English & $.56(.032)$ & $.72(.023)$ & $-.53(.041)$ & $-.43(.042)$ & $-.31(.032)$ & $.68(.024)$ \\
\hline \multicolumn{7}{|c|}{ Emotions/achievement grade 11} \\
\hline Mathematics & $.84(.019)$ & $.88(.016)$ & $-.77(.021)$ & $-.78(.026)$ & $-.56(.047)$ & $.76(.020)$ \\
\hline Physics & $.79(.022)$ & $.82(.023)$ & $-.70(.023)$ & $-.74(.027)$ & $-.57(.026)$ & $.60(.028)$ \\
\hline German & $.62(.045)$ & $.61(.045)$ & $-.55(.040)$ & $-.47(.055)$ & $-.44(.047)$ & $.68(.039)$ \\
\hline English & $.68(.036)$ & $.76(.028)$ & $-.68(.039)$ & $-.52(.045)$ & $-.46(.037)$ & $.67(.030)$ \\
\hline
\end{tabular}

Note: Grade 8 sample: $n=973$. Grade 11 sample: $n=737$. All coefficients are significant $(p<.001)$.

ment be evaluated as discrete constructs despite notable correla tions, the present results showing similar or weaker relations be tween self concept and emotions similarly underscore the importance of conceptually differentiating between these related constructs.

\subsection{Domain specificity of self concept/emotion relations}

In line with our second hypothesis, multi level analysis revealed that the strength of relations between self concept and emotional experiences clearly differed across domains. In other words, with in domain relations between self concept and emotions were found to be rather domain specific in nature. As anticipated, relations were stronger for the quantitative domains. This pattern of relations was also found to be consistent across grade levels. To account for why quantitative and language domains differ with respect to the magni tude of self concept/emotion relations an explanation might be that quantitative domains are more narrowly defined and have a more restricted range of classroom activities than do language domains (e.g., problem solving exercises vs. grammar training, readings, dis cussions, etc.; see Stodolsky \& Grossman, 1995, 2000). However, this assumption should be considered speculative in nature due to stu dents' perceptions of domain heterogeneity not having been investi gated in the present study. Nonetheless, the multi level approach adopted in this study could be used in subsequent research to further explore perceived heterogeneity as a moderator of self concept/emo tion relations within individuals (i.e., modeling slopes). For example, such an approach could be used to analyze whether students' per ceptions concerning the breadth of content and activities in a given domain significant impacts the strength of relationship between self concept and emotions.

\subsection{Age as a moderator of self concept/emotion relations}

Based on theoretical assumptions and empirical studies of 1 st to 6th grade students suggesting that specific subject domains be come increasingly perceived by students as discrete in nature with age, we hypothesized that the relations between academic self concept and emotions should be stronger for older than for youn ger students (cf., research on perceived competence and value in elementary school children; Eccles, Wigfield, Harold, \& Blumen feld, 1993; Wigfield et al., 1997). The results of the present study with 8 th and 11 th grade students support this hypothesis in show ing that for each of the four domains under investigation (mathe matics, physics, German, and English), the relations between academic self concept and emotions were stronger in the grade 11 sample than for grade 8 students.

Despite the consistency between these self concept/emotion relations and research on younger students, these findings are not consistent with Bong (2001) and Goetz et al. (2007) who found the within domain relations of motivational or emotional experiences (assessed separately) to be of similar magnitude for middle and high school students. However, it is important to note that this inconsistent finding was observed when assessing relations between self concepts and emotions. In other words, previous findings indi cate that within groups of constructs (i.e., among motivational mea sures, or among emotions measures), the strength of within domain relations is the same in middle and high school students. However, the present results showed that across these groups of con structs (i.e., between self concept and emotions), relations appear to be stronger among high school students. One explanation for this re sult may be that as children in achievement oriented societies be come increasingly aware of the high value placed on competence in adulthood, their self concepts become increasingly related to self worth and emotional well being over time. However, this assumption is speculative and warrants further investigation in lon gitudinal studies to determine whether self concept increases in subjective importance from childhood to adolescence.

\subsection{Emotion type as a moderator of self concept/emotion relations}

The fourth study hypothesis concerning emotion type as a mod erator of self concept/emotion relations followed from theoretical distinction between outcome and activity oriented emotions and on previous empirical results (Frenzel et al., 2007; Goetz, 2004; Goetz et al., 2006; Pekrun, 2006). Despite systematic patterns self concept/emotion relations across all emotions assessed, we found as expected that the strength of relations differed as a function of emotion type. The strongest relation between self con cept and emotion was observed for feelings of pride, which as a 
Grade 8

Mathematics

\begin{tabular}{|l|l|l|l|l|l|}
\hline Pride \\
Enjoyment \\
Anxiety \\
Bnger \\
Boredom
\end{tabular}

Fig. 3. Relations between academic self-concepts and emotions in different domains. Horizontal lines: depicted are absolute values of disattenuated correlation coefficients and their 95\% confidence intervals. Vertical lines: depicted is the average disattenuated correlation for each domain. These means were calculated as follows: (a) all 40 disattenuated correlation coefficients were subjected to Fisher's $z$ transformation; (b) for each domain and grade level the mean of the five $z$-values was calculated, resulting in eight means; and (c) these eight means were each re-transformed (Cohen, 1988).

clearly outcome based emotion was closely related to the out come oriented measure of academic self concept.

Contrary to our expectation that the outcome related emotion of anxiety would also be strongly related to academic self concept, this emotion showed notably weaker relations than pride. Anxiety/ self concept relations were of approximately the same magnitude as the relationships between self concept and enjoyment or anger, both of which are considered outcome and activity related emo tions and were expected to show weaker relations. One explana tion for this finding might be that students' feelings of anxiety may be determined by other salient antecedent factors in addition to achievement outcomes, such as parental expectations or nega tive feedback from parents or teachers after performing poorly. However, as empirical support for this assertion is beyond the scope of this study, more comprehensive future research is war ranted in which the relations between emotions and the influence of parents, teachers, and peers are assessed. Nonetheless, the pres ent findings for boredom were directly consistent with the study hypotheses, with this activity related emotion found to be most weakly related to self concept of all emotions measures. This find ing is also in line with previous studies showing boredom to have notably weaker relations with academic self concept than other academic emotions (e.g., Goetz, 2004; Goetz et al., 2006).

\section{Implications and future directions}

The present study findings have several important implications for research on academic self concept and emotions, as well as educational practice. The following outlines potential implications for future research on self concept/emotion relations as well as educational interventions aimed at fostering students' academic self concept and emotional experiences.

\subsection{Methodological issues}

Our results provide empirical support for the assessment of self concept and academic emotions as differentiated psychosocial variables. More specifically, although some observed relations between self concept and emotions were relatively strong at the latent level (e.g., self concept and pride), they were still weak en 
ough to warrant conceptual and empirical separation. However should researchers be required for the sake of efficiency to assess relations between a limited number of emotions and self concept, the present results may prove useful for selecting emotions that are most distinct from academic self concept. For example, bore dom was found in this study to be most weakly related to self con cept, and as such could justifiably be assessed in later research in which self concept is assessed in relation to non redundant emo tion constructs.

The present findings are also relevant for future studies on self concept and emotions in terms of conducting power analyses to determine appropriate sample sizes (e.g., estimating the magnitude of relations). The present self concept/emotion relations may also help researchers to anticipate the extent to which multicollinearity could pose a potential confound if two specific constructs are evalu ated simultaneously as independent variables. Our findings should allow for more specific estimates of relations between self concept and emotions with respect to specific subject areas, grade levels, as well as the specific emotions under investigation. For example, whereas the relation between self concept and boredom in German was rather weak in middle school students (disattenuated $r=-.23$ ), the relation between self concept and pride in mathematics was notably strong in high school students (disattenuated $r=.88$ ).

In addition to the afore mentioned implications are two impor tant factors limiting the generalizability of the present study find ings. First, due to the cross sectional and non experimental nature of the study design, the present findings do not provide evidence in support of directional, causal relations between academic self con cepts and emotions. However, the significant relations observed between self concept and emotions, controlling for achievement levels, are consistent with recent findings showing self concepts in mathematics and language classes to predict academic enjoy ment with prior achievement held constant (Goetz et al., 2008). Nevertheless, further longitudinal or experimental studies in which the magnitude and direction of causal effects between these constructs are evaluated may prove promising.

The second limitation concerns the study focus on students' habitual emotional experiences and self concepts in the academic domain. With respect to the trait/state distinction of emotion con structs (Cattell \& Scheier, 1961; Spielberger, 1972), this study thus pertained specifically to students' trait academic emotions and did not explore state based emotion relations. Similarly, students' per ceived competencies were also assessed as habitual constructs in a manner consistent with the existing self concept literature. Future research on the relations between students' momentary emotional experiences in given academic situations (state emotions) and temporally specific competency beliefs may also be beneficial. For example, state based assessments of emotions and perceived competence could be administered at various points throughout the school day using experience sampling methods (Csikszentmih alyi \& Larson, 1987; Hektner, Schmidt, \& Csikszentmihalyi, 2007), allowing for the variability of self concept/emotion relations with in persons to be explored (idiographic approach).

\subsection{Educational implications}

In addition to methodological considerations, the findings of this study may also assist in efforts to improve classroom instruc tion aimed at fostering students' emotional experiences. Consider ing the relations observed between academic self concept and emotions, and the hypothesized role of self concept as a critical antecedent of emotional experiences (cf., Scherer et al., 2001), one potentially effective way of fostering adaptive academic emo tions may be domain specific techniques focused on enhancing students' academic self concepts (see Goetz et al., 2008). In the educational research literature, a number of self concept enhanc ing methods have been suggested, such as adapting teaching to learning related individual differences to prevent students from becoming over challenged academically (Snow \& Swanson, 1992). Providing positive competence feedback specific to a stu dents' academic progress, thus highlighting individual growth as opposed to comparative achievement (individual frame of refer ence), should contribute to a more positive academic self concept (Burnett, 2003; Lüdtke, Köller, Marsh, \& Trautwein, 2005). Another strategy involves attempts to modify students' subjective beliefs concerning the reasons behind knowledge gains in a given subject area. For example, students could be encouraged to attribute their academic improvements to their individual competencies in that domain. Empirical research has consistently found that fostering a sense of personal control over academic development in strug gling students, by underscoring the importance of individual com petencies, can be beneficial for improving academic self concept (see Dresel \& Haugwitz, 2008; Perry \& Hall, 2009).

An additional and important implication of the present study is that the effectiveness of techniques for fostering students' emo tions by enhancing their academic self concept is expected to dif fer significantly depending on the subject domain, students' age, and the specific emotions assessed as outcome measures. The re sults of this study imply that self concept enhancing techniques should be most beneficial in the quantitative domains (e.g., math ematics, physics), among older students (e.g., high school popula tions), and in promoting the academic emotions of pride, followed by enjoyment, anxiety, and anger. However, students' experiences of boredom are likely to only be weakly impacted by improve ments in academic self concept.

In light of the anticipated periodic ineffectiveness of self con cept enhancing methods, teachers should also be aware of alterna tive methods for improving students' emotional experiences in the classroom. To this end, specific instruction methods can be used to increase positive emotions and decrease negative emotions (see Goetz et al., 2006; Pekrun, 2006), for example, displaying one's enthusiasm could facilitate student enjoyment (Frenzel, Goetz, Lüdtke, Pekrun, \& Sutton, 2009), assigning authentic tasks should reduce boredom, and shaping goal structures to promote a mastery orientation may reduce student anxiety (cf., Pekrun et al., 2006).

One of the primary goals of teachers is to prepare students to be come contributing members of an achievement oriented society in which lifelong knowledge acquisition is of critical importance. The quantity and quality of these learning experiences depends strongly upon maintaining adaptive levels of perceived competence and achievement related emotions in a given domain (see McCombs, 1991). The findings of the present study suggest that enhancing stu dents' academic self concept may serve to increase positive emotions and decrease negative emotions. Finally, these results also highlight the importance of accounting for the specific domain and age group under consideration, as well as the specific emotions assessed, all of which are factors that can significantly affect the extent to which stu dents' academic self concept is related to their emotions.

\section{Conclusion}

The present study provides empirical evidence toward address ing our initial research questions concerning the extent to which students' emotional experiences can be inferred from their per ceived competencies in the academic domain, and vice versa. Whereas the present findings demonstrate that such inferences are indeed possible, they further demonstrate the importance of three additional factors that significantly moderate the strength of these relations. First, our results suggest that the relations be tween academic self concept and emotions depend largely on the subject area in which these constructs are evaluated, with stronger relations observed in quantitative classes (mathematics, physics) 
as opposed to language classes (German, English). Second, findings showed self concept/emotion relations to also be moderated by grade level, with stronger relations found among older students (grade 11) as compared to younger students (grade 8). Third, our results indicate that relations between self concept and emotions differ significantly depending on the specific emotion assessed, with stronger relations generally observed for outcome related (e.g., pride) vs. activity related emotions (e.g., boredom). To sum marize, the present study offers empirical support for the concep tual differentiation of academic self concept and emotion constructs, and highlights the importance of moderating factors when evaluating the strength of relations between these psychoso cial measures in an academic setting.

\section{Appendix A. Self-concept and emotion scale items}

\begin{tabular}{|c|c|}
\hline \multicolumn{2}{|c|}{ Self concept } \\
\hline & I get good marks in [DOMAIN]. \\
\hline Sc_2 2 & [DOMAIN] is one of my best subjects. \\
\hline Sc_3 & I have always done well in [DOMAIN]. \\
\hline & I am hopeless in [DOMAIN] classes. [inverted] \\
\hline \multicolumn{2}{|c|}{ Enjoyment } \\
\hline $\mathrm{Ej}_{-} 1$ & I am looking forward to [DOMAIN] classes. \\
\hline $\mathrm{Ej} \_2$ & I enjoy my [DOMAIN] class. \\
\hline Ej_3 & $\begin{array}{l}\text { I enjoy my [DOMAIN] class so much that I am } \\
\text { strongly motivated to participate. }\end{array}$ \\
\hline Ej_4 & $\begin{array}{l}\text { The material we deal with in [DOMAIN] is so } \\
\text { exciting that I really enjoy my class. }\end{array}$ \\
\hline \multicolumn{2}{|l|}{ Pride } \\
\hline Pr_1 & $\begin{array}{l}\text { I think I can be proud of my knowledge in } \\
\text { [DOMAIN]. }\end{array}$ \\
\hline $\mathrm{Pr} \_2$ & $\begin{array}{l}\text { I am proud of the contributions I make in } \\
\text { [DOMAIN] classes. }\end{array}$ \\
\hline Pr_3 & $\begin{array}{l}\text { I take pride in being able to keep up with the } \\
\text { material in [DOMAIN] class. }\end{array}$ \\
\hline Pr_4 & In [DOMAIN] class I am proud of myself. \\
\hline \multicolumn{2}{|c|}{ Anxiety } \\
\hline Ax_1 & I feel tense and nervous in [DOMAIN] classes. \\
\hline$A \times 2$ & $\begin{array}{l}\text { I worry if the material in [DOMAIN] class is much } \\
\text { too difficult for me. }\end{array}$ \\
\hline Ax 3 & $\begin{array}{l}\text { When thinking of my [DOMAIN] class, I get } \\
\text { queasy. }\end{array}$ \\
\hline Ax_4 & $\begin{array}{l}\text { [DOMAIN] scares me so much that I would rather } \\
\text { not attend school. }\end{array}$ \\
\hline \multicolumn{2}{|l|}{ Anger } \\
\hline Ag_1 & I am angry in [DOMAIN] classes. \\
\hline $\mathrm{Ag} \_2$ & $\begin{array}{l}\text { I am so angry during my [DOMAIN] class that I } \\
\text { would like to leave. }\end{array}$ \\
\hline Ag_3 & $\begin{array}{l}\text { I get angry because the material in [DOMAIN] is } \\
\text { so difficult. }\end{array}$ \\
\hline Ag_4 & $\begin{array}{l}\text { Because I'm angry I get restless in [DOMAIN] } \\
\text { class. }\end{array}$ \\
\hline \multicolumn{2}{|c|}{ Boredom } \\
\hline Bo_1 & I get bored in [DOMAIN] classes. \\
\hline Bo_2 & $\begin{array}{l}\text { I can't concentrate in [DOMAIN] class because I } \\
\text { am so bored. }\end{array}$ \\
\hline Bo_3 & $\begin{array}{l}\text { I am so bored in [DOMAIN] class that I can't stay } \\
\text { awake. }\end{array}$ \\
\hline Bo_4 & $\begin{array}{l}\text { Just thinking of my [DOMAIN] class makes me } \\
\text { feel bored. }\end{array}$ \\
\hline
\end{tabular}

Note: DOMAIN: items each referred to the domains of mathematics, physics, German, and English.
Appendix B. Descriptive statistics for self-report and achievement measures

\begin{tabular}{|c|c|c|c|c|c|c|}
\hline \multirow[t]{2}{*}{ Scale } & \multicolumn{3}{|c|}{ Grade 8 (n 973) } & \multicolumn{3}{|c|}{ Grade $11(n$ 737) } \\
\hline & $M$ & $S D$ & $\alpha$ & $M$ & $S D$ & $\alpha$ \\
\hline \multicolumn{7}{|l|}{ Self concept } \\
\hline Mathematics & 3.16 & 1.21 & .91 & 3.19 & 1.26 & .92 \\
\hline Physics & 3.37 & 1.10 & .90 & 3.13 & 1.17 & .92 \\
\hline German & 3.39 & 0.91 & .82 & 3.37 & 0.98 & .85 \\
\hline English & 3.38 & 1.00 & .87 & 3.57 & 1.02 & .88 \\
\hline \multicolumn{7}{|l|}{ Enjoyment } \\
\hline Mathematics & 2.62 & 1.14 & .90 & 2.90 & 1.19 & .93 \\
\hline Physics & 2.85 & 1.10 & .90 & 2.63 & 1.11 & .92 \\
\hline German & 2.61 & 0.92 & .83 & 2.76 & 0.96 & .87 \\
\hline English & 2.95 & 0.96 & .85 & 3.07 & 1.00 & .89 \\
\hline \multicolumn{7}{|l|}{ Pride } \\
\hline Mathematics & 2.80 & 1.10 & .89 & 2.89 & 1.19 & .91 \\
\hline Physics & 2.84 & 1.07 & .91 & 2.66 & 1.08 & .91 \\
\hline German & 2.77 & 0.88 & .79 & 2.87 & 0.92 & .82 \\
\hline English & 2.99 & 0.94 & .86 & 3.12 & 1.00 & .89 \\
\hline \multicolumn{7}{|l|}{ Anxiety } \\
\hline Mathematics & 2.04 & 1.00 & .83 & 2.01 & 1.05 & .88 \\
\hline Physics & 1.84 & 0.89 & .84 & 1.90 & 0.95 & .86 \\
\hline German & 1.57 & 0.68 & .74 & 1.49 & 0.60 & .69 \\
\hline English & 1.74 & 0.83 & .82 & 1.54 & 0.72 & .82 \\
\hline \multicolumn{7}{|l|}{ Anger } \\
\hline Mathematics & 2.33 & 1.06 & .80 & 2.13 & 1.02 & .84 \\
\hline Physics & 2.04 & 0.98 & .82 & 2.16 & 1.01 & .82 \\
\hline German & 2.23 & 0.91 & .73 & 1.97 & 0.79 & .73 \\
\hline English & 2.01 & 0.88 & .77 & 1.79 & 0.82 & .79 \\
\hline \multicolumn{7}{|l|}{ Boredom } \\
\hline Mathematics & 2.49 & 1.12 & .86 & 2.25 & 1.09 & .90 \\
\hline Physics & 2.26 & 1.11 & .89 & 2.56 & 1.21 & .91 \\
\hline German & 2.85 & 1.14 & .89 & 2.70 & 1.11 & .89 \\
\hline English & 2.22 & 1.06 & .89 & 2.23 & 1.05 & .91 \\
\hline \multicolumn{7}{|l|}{ Achievement } \\
\hline Mathematics & 3.69 & 1.07 & & 3.76 & 1.17 & \\
\hline Physics & 4.07 & 1.06 & & 3.92 & 1.06 & \\
\hline German & 3.98 & 0.84 & & 3.98 & 0.88 & \\
\hline English & 3.80 & 0.95 & & 4.03 & 0.90 & \\
\hline
\end{tabular}

Note: Self-concept and emotion scales: means $(M)$ and standard deviations $(S D)$ refer to summative scales divided by the number of scale items; 4 items were used for each scale; response format consisted of a 5-point Likert scale ranging from (1) strongly disagree to (5) strongly agree. Achievement: grades are depicted; in the German school system, grades vary between 1 (very good) and 6 (insufficient). These grades measures were inverted, such that high values represent better achievement outcomes.

Appendix C. Zero-order correlation coefficients among selfconcept measures

\begin{tabular}{|c|c|c|c|c|}
\hline & SC mathematics & SC physics & SC German & SC English \\
\hline SC mathematics & & .57 & -.16 & -.15 \\
\hline SC physics & .44 & & -.11 & -.01 \\
\hline SC German & -.05 & .02 & & .26 \\
\hline SC English & -.01 & .05 & .32 & \\
\hline
\end{tabular}

Note: SC: self-concept. Grade 8 sample shown below the diagonal; $n=973 . p<.05 /$ $.01 / .001$ for $|r|>.06 / .08 / .11$. Grade 11 sample shown above the diagonal; $n=737$. $p<.05 / .01 / .001$ for $|r|>.07 \mid .10 / .12$. 
Appendix D. Zero-order correlation coefficients among emotions and achievement

\begin{tabular}{|c|c|c|c|c|c|c|c|c|c|c|c|c|c|c|c|c|c|c|c|c|c|c|c|c|}
\hline Scale & 1 & 2 & 3 & 4 & 5 & 6 & 7 & 8 & 9 & 10 & 11 & 12 & 13 & 14 & 15 & 16 & 17 & 18 & 19 & 20 & 21 & 22 & 23 & 24 \\
\hline \multicolumn{25}{|l|}{ Enjoyment } \\
\hline 1. Mathematics & & .47 & .02 & .00 & .84 & 4.46 & .08 & .01 & -.66 & -.31 & 1.06 & $\begin{array}{ll}6 & .08 \\
.\end{array}$ & -.74 & -.31 & .02 & 2.04 & $4-.70$ & -.34 & -.01 & -.03 & .62 & 2.45 & .07 & 7.04 \\
\hline 2. Physics & .38 & & .07 & .09 & .43 & .80 & .13 & .09 & -.31 & -.54 & $4 \quad .00$ & $0-.01$ & -.32 & -.70 & .02 & -.02 & $2-.32$ & -.73 & -.01 & -.06 & .24 & $\begin{array}{ll}4 & .51\end{array}$ & -.02 & 2.02 \\
\hline 3. German & .19 & .25 & & .22 & .01 & .06 & .66 & .16 & .11 & .05 & $5-.36$ & $\begin{array}{ll}6 & .05\end{array}$ & .06 & -.01 & -.63 & $3-.03$ & $3-.01$ & -.02 & -.71 & -.13 & $3-.06$ & $6-.05$ & .40 & .07 \\
\hline 4. English & .00 & .11 & .17 & & .03 & .10 & .31 & .74 & .08 & .09 & $9-.08$ & $8-.43$ & .05 & .02 & -.11 & -.65 & $5-.04$ & -.10 & -.14 & -.71 & -.06 & $6-.04$ & .05 & .39 \\
\hline \multicolumn{25}{|l|}{ Pride } \\
\hline 5. Math & .76 & .31 & .15 & .01 & & .56 & .19 & .11 & -.64 & -.30 & .07 & $\begin{array}{ll}7.11 \\
\end{array}$ & -.63 & -.26 & .05 & .06 & $6-.52$ & -.27 & .02 & -.02 & .62 & 2.46 & .08 & 3.05 \\
\hline 6. Physics & .35 & .77 & .21 & .09 & .46 & & .28 & .24 & -.33 & -.51 & 1.01 & $\begin{array}{ll}1 & .00\end{array}$ & -.30 & -.56 & .04 & $4 \quad .02$ & $2-.24$ & -.53 & .01 & -.05 & .28 & $8 \quad .53$ & .00 & .05 \\
\hline 7. $\mathrm{C}-1$ & .19 & .21 & .51 & .24 & .31 & .35 & & .44 & .10 & .05 & $5-.25$ & $\begin{array}{ll}5 & .01\end{array}$ & .08 & .02 & -.34 & $1-.05$ & $\begin{array}{ll}5 & .06 \\
\end{array}$ & -.04 & -.39 & -.13 & $3-.06$ & $\begin{array}{ll}6 & .00\end{array}$ & .34 & $\begin{array}{ll}4.09 \\
\end{array}$ \\
\hline 8. English & .07 & .14 & .14 & .65 & .23 & 32 & .43 & & .10 & .08 & $3-.07$ & $7-.41$ & .10 & .04 & -.04 & $4-.40$ & 02 & & -.02 & -.44 & $4-.03$ & $\begin{array}{ll}3 \quad .03 \\
\end{array}$ & .06 & .44 \\
\hline \multicolumn{25}{|l|}{ Anxiety } \\
\hline 9. Mathematics & -.55 & -.14 & -.02 & .15 & -.51 & -.14 & .05 & .11 & & .58 & 3.13 & $\begin{array}{ll}3 & .08\end{array}$ & .82 & .45 & .05 & .08 & 8.52 & .29 & -.01 & .08 & $3-.57$ & $7-.41$ & -.05 & -.07 \\
\hline 1 & -.17 & -.53 & -.09 & .03 & -.17 & -.41 & -.01 & .04 & .46 & & .20 & 0.21 & .46 & .80 & 99 & .11 & $\begin{array}{ll}1 & .25 \\
\end{array}$ & .46 & .05 & .04 & $4-.26$ & $6-.48$ & -.04 & -.06 \\
\hline 1 & .02 & -.01 & -.30 & -.01 & .06 & .05 & -.13 & .02 & .20 & .29 & & .30 & .08 & .19 & .58 & 3.21 & $\begin{array}{ll}1 & .01\end{array}$ & .07 & .32 & .18 & -.08 & $8-.07$ & -.38 & $3-.19$ \\
\hline 12. English & .13 & .02 & -.01 & -.40 & .10 & .05 & .03 & -.29 & .15 & .25 & 5.28 & & .06 & .18 & .13 & 3. .62 & 2.05 & .13 & .01 & .35 & $5-.04$ & $4-.10$ & -.06 & -.45 \\
\hline \multicolumn{25}{|l|}{ Anger } \\
\hline 1. & -.68 & -.20 & -.13 & .08 & -.54 & -.14 & -.01 & .07 & .78 & 36 & 5 $\quad .19$ & $\begin{array}{ll}9 & .09\end{array}$ & & .45 & .11 & .12 & $\begin{array}{ll}2 & .71\end{array}$ & .35 & .06 & .12 & -.59 & $9-.39$ & -.07 & -.10 \\
\hline & -.25 & -.68 & -.16 & -.02 & -.17 & -.46 & -.05 & .03 & .39 & .79 & $\begin{array}{l}9 \\
9\end{array}$ & $\begin{array}{ll}6 & .18\end{array}$ & .43 & & .16 & .16 & $\begin{array}{ll}5 & .31\end{array}$ & .68 & 10 & .11 & $1-.22$ & $2-.49$ & -.03 & -.09 \\
\hline han & -.11 & -.13 & -.61 & -.03 & -.02 & -.06 & -.22 & .00 & .19 & .28 & 3.58 & $8 \quad .22$ & .31 & .32 & & .25 & $5 \quad .11$ & .09 & .70 & .24 & $4-.05$ & $5-.02$ & -.34 & $4-.16$ \\
\hline 16. English & .08 & .02 & -.10 & -.60 & .10 & .08 & -.04 & -.33 & .09 & .17 & 7.30 & .67 & .14 & .20 & .33 & & .09 & .16 & .15 & .74 & $4-.01$ & $1-.01$ & -.02 & -.36 \\
\hline \multicolumn{25}{|l|}{ Boredom } \\
\hline 17. 1 & -.68 & -.23 & -.12 & .00 & -.43 & -.15 & -.11 & -.04 & .52 & .21 & 1. 14 & $\begin{array}{ll}4 \quad .08 \\
4\end{array}$ & .74 & .33 & .24 & .15 & & .48 & .14 & .15 & -.43 & $3-.28$ & -.04 & -.06 \\
\hline sics & -.23 & -.70 & -.17 & -.07 & -.13 & $3-.43-$ & -.10 & -.05 & .21 & .52 & .17 & $\begin{array}{ll}7 & .14\end{array}$ & .29 & .77 & .25 & .17 & $\begin{array}{ll}7 & .35\end{array}$ & & .09 & .19 & -.18 & $8-.34$ & .03 & -.04 \\
\hline & -.14 & -.18 & -.70 & -.08 & -.08 & -.14 & -.26 & -.04 & .14 & .22 & .36 & 5.15 & .24 & .27 & .71 & .22 & 2.23 & .25 & & .24 & $4 \quad .02$ & 2.02 & -.27 & -.06 \\
\hline 20. English & .04 & -.05 & -.08 & -.64 & .07 & 7.02 & -.04 & -.31 & .04 & .13 & .18 & 3.31 & .10 & .16 & .21 & .67 & 7.14 & .20 & .18 & & -.03 & 3.00 & -.02 & -.28 \\
\hline \multicolumn{25}{|l|}{ Achievemer } \\
\hline 21. Mathematics & .40 & .10 & -.04 & -.08 & .49 & .12 & -.02 & & -.45 & -.18 & $3-.05$ & $5-.04$ & -.42 & -.16 & -.06 & -.03 & $3-.28$ & -.10 & -.04 & .00 & & .63 & .32 & .32 \\
\hline 22. $\mathrm{P}$ & .21 & .38 & -.03 & -.09 & .26 & .42 & .00 & .03 & -.28 & -.39 & -.06 & -.02 & -.22 & -.39 & -.08 & .01 & $1-.13$ & -.25 & -.08 & .01 & .57 & & .29 & .34 \\
\hline & .04 & .01 & .22 & .05 & .05 & -.02 & .20 & .05 & -.09 & -.08 & $3-.34$ & $4-.16$ & -.11 & -.07 & -.32 & -.18 & $3-.10$ & -.04 & -.18 & -.08 & 3.36 & $\begin{array}{ll}6 & .36\end{array}$ & & .43 \\
\hline 24. English & -.05 & -.06 & .01 & .26 & .01 & -.05 & .03 & .33 & -.05 & -.04 & -.17 & $7-.38$ & -.04 & -.04 & -.14 & $1-.34$ & $4-.05$ & -.05 & -.08 & -.17 & .43 & $\begin{array}{ll}3 & .38\end{array}$ & .53 & \\
\hline
\end{tabular}

Note: Grade 8 sample shown below the diagonal; $n=973 . p<.05 / .01 / .001$ for $|r|>.06 / .08 / .11$. Grade 11 sample shown above the diagonal; $n=737 . p<.05 / .01 / .001$ for $|r|>.07 \mid$ $.10 / .12$.

Appendix E. Zero-order correlations between self-concepts and emotions/achievement

\begin{tabular}{|c|c|c|c|c|c|c|c|c|c|c|c|c|c|c|c|c|c|c|c|c|c|c|c|c|}
\hline \multirow[b]{2}{*}{ Self concept } & \multicolumn{6}{|c|}{ Mathematics } & \multicolumn{6}{|c|}{ Physics } & \multicolumn{6}{|c|}{ German } & \multicolumn{6}{|c|}{ English } \\
\hline & $\mathrm{Ej}$ & $\mathrm{Pr}$ & $A x$ & $\mathrm{Ag}$ & Bo & Ach & $\mathrm{Ej}$ & $\mathrm{Pr}$ & $\mathrm{Ax}$ & $\mathrm{Ag}$ & Bo & Ach & $\mathrm{Ej}$ & $\mathrm{Pr}$ & $\mathrm{Ax}$ & $\mathrm{Ag}$ & Bo & Ach & $\mathrm{Ej}$ & $\operatorname{Pr}$ & $\mathrm{Ax}$ & $\mathrm{Ag}$ & Bo & Ach \\
\hline \multicolumn{25}{|c|}{ Emotions/achievement in grade 8} \\
\hline 0 & .64 & .75 & -.66 & -.62 & -.42 & & & .27 & -.30 & -.27 & -.15 & .44 & .02 & 04 & 1.00 & -.05 & -.07 & .15 & -.09 & .01 & .00 & .03 & 03 & .13 \\
\hline $\mathrm{Ph}$ & .28 & 4 & -.29 & -.23 & -.15 & & & & & & -.44 & & 4 & 07 & -.01 & -.06 & 12. & .09 & -.03 & .10 & -.02 & .05 & -.01 & .09 \\
\hline & -.01 & -.02 & .04 & -.02 & -.05 & .0 & .04 & .05 & -.06 & -.07 & -.07 & . & .39 & 44 & -.47 & -.42 & -.23 & .62 & .13 & .15 & -.14 & $4-.19$ & -.12 & .27 \\
\hline Engl & -.10 & -.02 & .07 & .07 & -.01 & .11 & 03 & .00 & & 1 & -.03 & .10 & .05 & .15 & -.16 & & -.05 & .31 & .51 & .62 & -.50 & -.45 & -.29 & .68 \\
\hline \multicolumn{25}{|c|}{ Emotions/achievement in grade 11} \\
\hline 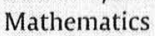 & .80 & .82 & -.74 & -.72 & -.5 & .77 & & .43 & -.41 & -.35 & -.30 & .56 & -.10 & -.04 & 2 & 94 & .05 . & & -.07 & -.07 & .03 & & -.01 & .11 \\
\hline PI & .46 & .47 & -.45 & -.40 & -.27 & .42 & .74 & .76 & -.69 & -.69 & -.53 & .73 & -.05 & .03 & -.02 & .01 & .02 & .05 & -.01 & .04 & -.09 & -.03 & -.05 & .14 \\
\hline & -.15 & -.13 & .16 & .11 & .10 & -.02 & -.08 & -.07 & .07 & .02 & .04 & .01 & .56 & .52 & -.48 & -.46 & -38 & .69 & .16 & .15 & -.09 & -.10 & -.09 & .26 \\
\hline English & -.18 & -.16 & .14 & .12 & .10 & -.03 & .06 & -.01 & .03 & .01 & .02 & .03 & .05 & .18 & -.20 & -.11 & -.01 & .1 & .63 & .69 & -.61 & -.51 & -.42 & .65 \\
\hline
\end{tabular}

Note: Ej: enjoyment. Pr: pride. Ax: anxiety. Ag: anger. Bo: boredom. Ach: achievement. Grade 8 sample: $n=973 . p<.05 / .01 / .001$ for $|r|>.06 / .08 / .11$. Grade 11 sample: $n=737$. $p<.05 / .01 / .001$ for $|r|>.07 / .09 / .12$.

\section{References}

Bandura, A. (1977). Social learning theory, Englewood Cliffs, N]: Prentice-Hall. Bandura, A. (1989). Human agency in social cognitive theory. American Psychologist, 44. $1175-1184$

Bandura, A. (1997). Self-efficacy. The experience of control. New York: W.H. Freeman and Company.

Bauer. D. J. (2003). Estimating multilevel linear models as structural equation models. Journal of Educational and Behavioral Statistics, 28(2), 135-167.
Bentler, P. M. (1990). Comparative fit indexes in structural models. Psychological Bulletin, 107, 238-246.

Bong, M. (2001). Between- and within-domain relations of acadenic motivation among middle and high school students: Self-efficacy, task-value and achievement goals. Journal of Educational Psychology, 93(1), 23-34.

Bong, M., \& Clark, R. E. (1999). Comparison between self-concept and self-efficacy in academic motivation research. Educational Psychologist, 34, 139-153.

Bong, M., \& Skaalvik, E. M. (2003). Academic self-concept and self-efficacy: How different are they really? Educational Psychology Review, 15(1), 1-40. 
Brunswik, E. (1952). The conceptual framework of psychology. Oxford, England: University Chicago Press.

Burnett. P. C. (2003). The impact of teacher feedback on student self-talk and selfconcept in reading and mathematics. Journal of Classroom Interaction, 38, 11-16.

Byrne, B. M. (1996). Measuring self-concept across the life span: Issues and instrumentation. Washington, DC: American Psychological Association.

Cattell, R. B., \& Scheier, I. H. (1961). The meaning and measurement of neuroticism and anxiety. New York: Ronald Press.

Chapman, J. W., \& Turner, W. E. (1995). Development of young children's reading self-concepts: An examination of emerging subcomponents and their relationship with reading achievement. Journal of Educational Psychology, 87. 154-167.

Cohen, J. (1988). Statistical power analysis for the behavioural sciences. San Diego, CA: Academic Press.

Cohen, J. (1992). A power primer. Psychological Bulletin, 112, 155-159.

Csikszentmihalyi, M., \& Larson, R. (1987). Validity and reliability of the ExperienceSampling Method. Journal of Nervous and Mental Diseases, 9, 526-536.

Damasio, A. R. (2004). Emotions and feelings: A neurobiological perspective. In A. S. R. Manstead, N. Frijda, \& A. Fischer (Eds.), Feelings and emotions (pp. 49-57). Cambridge, UK: Cambridge University Press.

Deci, E. L., \& Ryan, R. M. (1985). Intrinsic motivation and selfdetermination in human behavior. New York: Plenum Press.

Dresel, M., \& Haugwitz, M. (2008). A computer based approach to fostering motivation and self-regulated learning. The Journal of Experimental Education, 77(1), 3-20.

Dweck, C. S. (1986). Motivational processes affecting learning. American Psychologist, 41, 1040-1048.

Eccles, J. S., Wigfield, A., Harold, R. D., \& Blumenfeld, P. (1993). Age and gender differences in children's self- and task perceptions during elementary school. Child Development, 64, 830-847.

Efklides, A., \& Volet, S. (2005). Feelings and emotions in the learning process [Special issue]. Learning and Instruction, 15(5).

Fellous, J.-M., \& LeDoux, J. E. (2005). Toward basic principles for emotional processing: What the fearful brain tells the robot. In J.-M. Fellous \& M. E. Arbib (Eds.). Who needs emotions? The brain meets the robot (pp. 79-115). New York, NY: Oxford University Press.

Frenzel, A. C., Goetz, T., Lüdtke, O., Pekrun, R., \& Sutton, R. E. (2009). Emotional transmission in the classroom: Exploring the relationship between teacher and student enjoyment. Journal of Educational Psychology, 101(3), 705-716.

Frenzel, A. C., Pekrun, R., \& Goetz, T. (2007). Girls and mathematics - A "hopeless" issue? A control-value approach to gender differences in emotions towards mathematics. European Journal of Psychology of Education, 22(4), 497-514.

Goetz, T. (2004). Emotionales Erleben und selbstreguliertes Lernen bei Schülern im Fach Mathematik [Students' emotions and self-regulated learning in mathematics]. Muenchen: Utz.

Goetz, T. Frenzel, C. A., Hall, N. C., \& Pekrun, R. (2008). Antecedents of academic emotions: Testing the internal/external frame of reference model for academic enjoyment. Contemporary Educational Psychology, 33, 9-33.

Goetz, T., Frenzel, C. A., Pekrun, R., Hall, N. C., \& Lüdtke, O. (2007). Between- and within-domain relations of students' academic emotions. Journal of Educational Psychology, 99(4), 715-733.

Goetz, T., Hall, N. C., Frenzel, A. C., \& Pekrun, R. (2006). A hierarchical conceptualization of enjoyment in students. Learning and Instruction, 16(4), 323-338.

Goetz, T., Pekrun, R., Hall, N. C., \& Haag, L. (2006). Academic emotions from a socialcognitive perspective: Antecedents and domain specificity of students' affect in the context of Latin instruction. British Journal of Educational Psychology, 76(2), 289-308.

Hektner, J. M., Schmidt, J. A., \& Csikszentmihalyi, M. (2007). Experience sampling method: Measuring the quality of everyday life. Thousand Oaks, CA: Sage.

Henson, H. N., \& Chang, E. C. (1998). Locus of control and the fundamental dimensions of moods. Psychological Reports, 82, 1335-1338.

Hox, J. J. (2002). Multilevel analysis: Techniques and applications. Mahwah, NJ: Lawrence Erlbaum Associates.

Kleinginna, P. R., \& Kleinginna, A. M. (1981). A categorized list of emotion definitions, with suggestions for a consensual definition. Motivation and Emotion, 5, 345-379.

Lewis, M., \& Haviland-Jones, J. M. (Eds.). (2000). Handbook of emotions. New York: Guilford.

Kunter, M., Schümer, G, Artelt, C., Baumert, J., Klieme, E., Neubrand, M., et al. (2002). PISA 2000: Dokumentation der Erhebungsinstrumente IPISA 2000: Documentation of scales]. Berlin: Heenemann $\mathrm{GmbH}$ and $\mathrm{Co.}$.

Linnenbrink, E. A. (2006). Emotion research in education: Theoretical and methodological perspectives on the integration of affect, motivation, and cognition [Special issue]. Educational Psychology Review, 18(4), 307-314.

Lüdtke, O., Köller, O., Marsh, H. W., \& Trautwein, U. (2005). Teacher frame of reference and the big-fish-little-pond effect. Contemporary Educational Psychology, 30, 263-285.

Marsh, H. W. (1988). Self Description Questionnaire: A theoretical and empirical basis for the measurement of multiple dimensions of preadolescent self-concept: A tes manual and a research monograph. San Antonio, TX: Psychological Corporation.

Marsh, H. W. (1989). Confirmatory factor analyses of multitrait-multimethod data: Many problems and a few solutions. Applied Psychological Measurement, 13, 335-361.

Marsh, H. W. (1990). Self-Description Questionnaire (SDQ) II: A theoretical and empirical basis for the measurement of multiple dimensions of adolescent self- concept: An interim test manual and a research monograph. Macarthur, New South Wales, Australia: University of Western Sydney.

Marsh, H. W. (1993). Academic self-concept: Theory, measurement and research. In J. Suls (Ed.). Psychological perspectives on the self (Vol. 4, pp. 59-98). Hillsdale, NJ: Erlbaum.

Marsh, H. W. \& Ayotte, V. (2003). Do multiple dimensions of self-concept become more differentiated with age? The differential distinctiveness hypothesis. Journal of Educational Psychology, 94(4), 687-706.

Marsh, H. W., \& Craven, R. (1997). Academic self-concept: Beyond the dustbowl. In G. D. Phye (Ed.), Handbook of classroom assessment (pp. 131-198). San Diego, CA: Academic Press.

Marsh, H. W., Craven, R. G., \& Debus, R. (1999). Separation of competency and affect components of multiple dimensions of academic self- concept: A developmental perspective. Merrill-Palmer Quarterly, 45, 567-601.

Marsh, H. W., Craven, R. G.. \& Mclnerney, D. M. (2003). International advances in selfresearch. Greenwich, CT: Information Age Publishing.

Marsh, H. W., \& O'Mara, A. (2008). Reciprocal effects between academic selfconcept, self-esteem, achievement, and attainment over seven adolescent years: Unidimensional and multidimensional perspectives of self-concept. Personality and Social Psychology Bulletin, 34(4), 542-552.

Marsh, H. W., \& O'Neill, R. (1984). Self Description Questionnaire III: The construct validity of multidimensional self-concept ratings by late adolescents. Journal of Educational Measurement, 21, 153-174.

Marsh, H. W., \& Shavelson, R. (1985). Self-concept: Its multifaceted, hierarchical structure. Educational Psychologist, 20, 107-125.

Marsh. H. W. \& Yeung. A. S. (1996). The distinctiveness of affects in specific school subjects: An application of confirmatory factor analysis with the National Educational Longitudinal Study of 1988. American Educational Research Journal, 33(3), 665-689.

McCombs, B. L. (1991). Motivation and lifelong learning. Educational Psychologist. 26(2), 117-127.

Mehta, P. D., \& Neale, M. C. (2005). People are variables too: Multilevel structural equations modeling. Psychological Methods, 10(3), 259-284.

Muthén, L. K., \& Muthén, B. O. (1998-2007). Mplus user's guide (5th ed.). Los Angeles. CA: Muthén and Muthén.

Organisation for Economic Cooperation and Development (2001). Knowledge and skills for life. First results from the OECD programme for international student assessment (PISA) 2000. Paris: Author.

Pekrun, R. (2006). The control-value theory of achievement emotions: Assumptions, corollaries, and implications for educational research and practice. Educational Psychology Review, 18, 315-341

Pekrun, R., Elliot, A. J., \& Maier, M. A. (2006). Achievement goals and discrete achievement emotions: A theoretical model and prospective test. Journal of Educational Psychology, 98(3), 583-597.

Pekrun, R., Goetz, T. \& Frenzel, A. C. (2005). Achievement Emotions Questionnaire Mathematics (AEQ-M) - User's manual. University of Munich: Department of Psychology.

Pekrun, R., Goetz, T., Titz, W., \& Perry, R. P. (2002). Academic emotions in students' self-regulated learning and achievement: $A$ program of qualitative and quantitative research. Educational Psychologist, 37(2), 91-105.

Perry, R. P. \& Hall, N. C. (2009). Attributional retraining. In E. M. Anderman \& L. H. Anderman (Eds.), Psychology of classroom learning: An encyclopedia. Farmington Hills, MI: Thomson Gale.

Rasbash, J., Browne, W., Healy, M., Cameron, B., \& Charlton, C. (2001). The MLwiN software Package version 1.10.2007 [Computer Software]. London: Institute of Education.

Raudenbush, S. W., \& Bryk, A. S. (2002). Hierarchical linear models (2nd ed.). Applications and data analysis methods. Thousand Oaks: Sage.

Reeve, J., Deci, E. L., \& Ryan, M. R. (2004). Self-determination theory: A dialectical framework for understanding sociocultural influences on student motivation. In D. M. McInerney \& S. V. Etten (Eds.). Big theories revisited: Research on sociocultural influences on motivation and learning (Vol. 4, pp. 31-60). Greenwich, CT: Information Age Publishing.

Ruthig.J. C., Perry, R. P.. Hladkyj, S., Hall, N. C., Pekrun, R., \& Chipperfield, J. G. (2008) A longitudinal analysis of perceived control and emotions in an academic setting. Social Psychology of Education, 11, 161-180.

Scherer, K. R. (1984). On the nature and function of emotion: A component process approach. In K. R. Scherer \& P. Ekman (Eds.), Approaches to emotion (pp. 293-317). Hillsdale, NJ: Erlbaum.

Scherer, K. R., Schorr, A., \& Johnstone, T. (Eds.). (2001). Appraisal processes in emotion. Oxford, UK: Oxford University Press.

Schutz, P. A., \& Pekrun, R. (Eds.). (2007). Emotions in education. San Diego, CA: Elsevier

Shavelson, R. J., Hubner, J. J., \& Stanton, G. C. (1976). Self-concept: Validation of construct interpretations. Review of Educational Research, 46(3), 407-441.

Shell, D. F., \& Husman, J. (2008). Control, motivation, affect and strategic selfregulation in the college classroom: A multidimensional phenomenon. Journal of Educational Psychology, 100, 443-459.

Skaalvik, E. M., \& Skaalvik, S. (2008). Self-concept and self-efficacy in mathematics: Relation with mathematics motivation and achievement. In F. M. Olsson (Ed.) New developments in the psychology of motivation (pp. 105-128). Hauppauge, NY, US: Nova Science Publishers.

Skinner, E. A. (1996). A guide to constructs of control. Journal of Personality and Social Psychology, 71(3), 549-570.

Snow, R. E., \& Swanson, J. (1992). Instructional psychology: aptitude, adaptation, and assessment. Annual Review of Psychology, 43, 586-626. 
Spielberger, C. D. (1972). Anxiety as an emotional state. In C. D. Spielberger (Ed.) Anxiety: Current trends in theory and research (Vol. 1, pp. 23-49). New York: Academic Press.

Steiger, J. H., \& Lind, J. C. (1980). Statistically based tests for the number of commo factors. In Paper presented at the psychometric society annual meeting, June.

Stipek, D. J., \& Mac Iver, D. (1989). Developmental change in children's assessment of intellectual competence. Child Development, 60, 521-538.

Stodolsky, S. S., \& Grossman, P. L. (1995). The impact of subject matter on curricular activity: An analysis of five academic subjects. American Educational Research Journal, 32(2), 227-251

Stodolsky, S. S., \& Grossman, P. L. (2000). Changing students, changing teaching. Teacher College Record, 102, 125-172.
Trautwein, U., Luedtke, O., Marsh, H. W., Koeller, O., \& Baumert, J. (2006). Tracking. grading, and student motivation: Using group composition and status to predict self-concept and interest in ninth-grade mathematics. Journal of Educationa Psychology, 98(4), 788-806.

Tucker, L. R., \& Lewis, C. (1973). A reliability coefficient for maximum likelihood factor analysis. Psychometrika, 38(1), 1-10.

Wigfield, A. (1994). Expectancy-value theory of achievement motivation: A developmental perspective. Educational Psychology Review, 6, 49-78.

Wigfield, A., Eccles, J. S., Yoon, K. S., Harold, R. D., Arbreton, A., Freedman-Doan, K. et al. (1997). Change in children's competence beliefs and subjective task value across the elementary school years: A three-year study. Journal of Educational Psychology, 89, 451-569. 